\title{
Peptide Functionalization of Silicon for Detection and Classification of Prostatic Cells
}

\author{
Jane Politi, ${ }^{1}$ Silvia Zappavigna, ${ }^{2}$ Ilaria Rea, ${ }^{1}$ Paolo Grieco, ${ }^{3}$ Alessandro Caliò, ${ }^{1}$ \\ Amalia Luce, ${ }^{2}$ Michele Caraglia, ${ }^{2}$ and Luca De Stefano ${ }^{1}$ \\ ${ }^{1}$ Institute for Microelectronics and Microsystems, Unit of Naples, National Research Council, Naples, Italy \\ ${ }^{2}$ Department of Biochemistry, Biophysics and General Pathology, University of Campania "L. Vanvitelli", Naples, Italy \\ ${ }^{3}$ Department of Pharmacy, University of Naples "Federico II", Naples, Italy
}

Correspondence should be addressed to Luca De Stefano; luca.destefano@na.imm.cnr.it

Received 9 February 2017; Accepted 24 July 2017; Published 30 August 2017

Academic Editor: Mike McShane

Copyright (C) 2017 Jane Politi et al. This is an open access article distributed under the Creative Commons Attribution License, which permits unrestricted use, distribution, and reproduction in any medium, provided the original work is properly cited.

\begin{abstract}
The development of simple, rapid, and low cost methods for early detection, identification, and measurement of multiple biomarkers remains a challenge to improve diagnosis, treatment monitoring, and prognosis of cancer. Biosensing technology, combining the properties of biological systems with functional advanced materials, guarantees rapid, reproducible, and highly sensitive cell detection. In this study, we developed silicon-based biochips for prostate cancer PC3 cells detection by using cytokeratin $8 / 18$ and Urotensin Receptor (UTR) as markers in order to obtain a biochip-based diagnostic system. Spectroscopic ellipsometry and fluorescence microscopy were used to characterize surface homogeneity and chemical properties. Cell detection was investigated by optical microscopy. Moreover, synthetic fluorescently labeled peptides were prepared and used for developing faster and lowercost identification assay compared with classic ELISA immunoassay. Results showed an effective immobilization of PC3 cells on silicon surface and the specific recognition of these cells by fluorescent Urotensin II (4-11). In conclusion, this strategy could be really useful as diagnostic system for prostate cancer.
\end{abstract}

\section{Introduction}

Prostate cancer is the most common malignant tumor in men and for this reason it is one of the most studied types from the point of view of diagnostics and therapeutics. In the last two decades, prostate cancer diagnosis has been based on the detection of serum prostate-specific antigen (PSA) levels and digital rectal examination. Unfortunately, the use of PSA levels in clinical practice remains controversial since several conditions (including medications, ejaculation, and prostate manipulation) can alter its levels [1].

In malignant tumors, the presence of metastasis accounts for the majority of cancer-related deaths owing to poor response to anticancer therapies [2]; therefore early detection of metastasis plays a key role in increasing survival in many cancers [3]. Prostate cancer cells are frequently present in peripheral blood circulation of men with advanced disease; metastatic deposits occur preferably in the bones leading to $84 \%$ of men's death and are directly responsible for a significant morbidity in time to death $[4,5]$. Epithelial cells of prostate rapidly bind the endothelium by an integrinmediated process $[6,7]$. Once bound, they migrate through the endothelial layer and then can infiltrate the bone marrow, peripheral blood, lymph nodes, stomach, or the penis to form metastases. Prostate cancer cell lines can be classified as to their metastatic destination: PC3, deriving by bone metastasis typically associated with advanced tumor and LNCaP that derive by lymph node metastasis occurring in the early stages of tumor [8].

In this light, these cells represent a good in vitro model for the design and evaluation of new assays to detect diagnostic or prognostic markers in prostate cancer.

The characterization of ligand-receptors interactions in tumor cells could become useful in the diagnosis of tumors and in directing the choice of opportune therapeutic options [9-13]. Epithelial cells in general, and epithelial derived tumor cells in particular, express the epithelial cell adhesion protein (EpCAM) and different cytokeratins (CKs), which are absent 


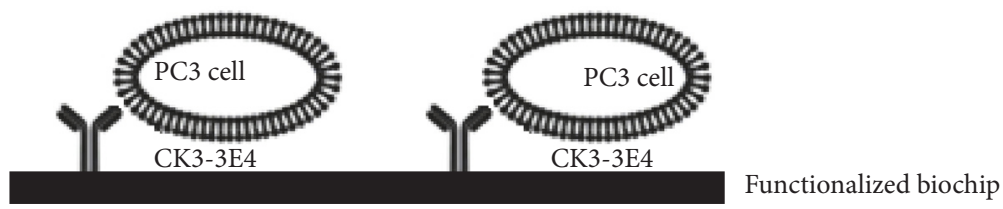

FIGURE 1: Schematic representation of biochip-based detection assay.

in normal white blood cells [14]. In particular, keratin 8 and keratin $18(\mathrm{CK} 8 / 18)$ are the first pair to be expressed in embryogenesis; they are involved in different regulatory functions, such as protein targeting/trafficking and apoptosis [14]. Further, CK8/18 are overexpressed in adenocarcinomas and contribute to neoplastic transformation [14]. Growing interest of scientist is shown also for Urotensin II (UT-II) receptors. Urotensin II (UT-II) and its receptor (UTR) are involved in the occurrence and development of different epithelial cancers. It was reported that cell growth, motility, and invasiveness in human bladder, prostate, and colorectal cancer cells were regulated by U-II/UTR axis. Moreover, our recent data suggested that UTR acts as a prognostic marker in human prostate adenocarcinoma patients [15].

Biosensors and biochips are emerging as effective tools for biomedical research and diagnostics having such advantages as low costs and short analysis times, and they are more and more used as commercial medical diagnostic devices [16].

Biosensors are analytical devices constituted by the molecular recognition element and the transducer material. The recognition elements can be biological molecules, such as DNA single strand, proteins, enzymes, and even whole cells that are coupled to different modes of transduction. Transduction mode can include different approaches, such as electrochemical, optical, and mass measurement. The biological event induces a measurable change in a solution property, which the transducer converts into an electrical signal that can be quantified [17]. Biosensors are easy to use and miniaturize and guarantee robust results compared with classical analytical techniques such as immunohistochemistry or ELISA [18]. In the last years, several labelfree biosensing devices have been developed in order to detect clinical relevant molecules (including glucose, HCG, or cardiac markers for diabetes and cardiac diseases) $[19,20]$.

Here, we propose developing a device based on crystalline silicon-based biochips for prostate cancer PC3 cells detection by using CK8/18 and UTR as markers in order to obtain a new diagnostic system. This will lead to the development of basic diagnostic kits that will be of help in the diagnosis of cancer and/or to the discovery of novel markers. The strategy includes the chemical functionalization of the silicon surface by using bifunctional linker molecules, the anchoring to the functionalized surface of specific antibodies, and the assay of the biochip activity by evaluating its ability to reveal the corresponding antibody expressed on membrane cells.

\section{Materials and Methods}

2.1. Biofunctionalization of Silicon Wafer. Crystalline silicon (cSi) $(0.001 \Omega \mathrm{cm}$ resistivity, $\langle 100\rangle$ oriented, $500 \mu \mathrm{m}$ thick) surface was passivated by thermal oxidation at $1050^{\circ} \mathrm{C}$ for 5 hours under nitrogen flux of $16.991 / \mathrm{h}$ and oxygen flux of $0.2 \mathrm{l} / \mathrm{min}$. Silicon dioxide was treated in piranha solution $\left(\mathrm{H}_{2} \mathrm{SO}_{4}: \mathrm{H}_{2} \mathrm{O}, 4: 2\right)$ at room temperature (RT) for 30 minutes in order to activate $\mathrm{Si}-\mathrm{O}-\mathrm{Si}$ in $\mathrm{Si}-\mathrm{OH}$ groups on silicon surface. After extensive washes with distilled water and drying under $\mathrm{N}_{2}$, chips were treated with a solution of $5 \%$ APTES ((3-aminopropyl)triethoxysilane) (Sigma Aldrich) in anhydrous toluene for 30 minutes at room temperature. Subsequently, the chips were washed with anhydrous toluene three times, cured on heater at $100^{\circ} \mathrm{C}$ for 10 minutes, and washed again twice with anhydrous toluene. The chips were then treated with cross-linker $\mathrm{BS}^{3}$ (bis[sulfosuccinimidyl] suberate) (Thermo Scientific) $1.6 \mathrm{mM}$ in PBS $1 \mathrm{x} \mathrm{pH}=7.4$ at $4^{\circ} \mathrm{C}$ for $5 \mathrm{~h}$, washed three times with PBS $1 \mathrm{x}$ and once with deionized water. Three chips were incubated at $4^{\circ} \mathrm{C}$ overnight with FITC- (fluorescein isothiocyanate-) labeled protein A $\left(\right.$ PrA $\left.^{*}\right)$ (Sigma Aldrich) diluted in PBS 1x $\mathrm{pH}=$ 7.4 at three concentrations (sample $\mathrm{C} 1: 1 \mathrm{mg} / \mathrm{mL}$; sample $\mathrm{C} 2$ : $2 \mathrm{mg} / \mathrm{mL}$; sample C3: $3 \mathrm{mg} / \mathrm{mL}$ ) and then they were washed three times with PBS $1 \mathrm{x}$ and once with deionized water. As reference sample for fluorescence measurements a biochip functionalized up to BS3 (sample C4) was used. After this experiment, four new chips were functionalized as described above using protein A (PrA) from S. aureus (Sigma Aldrich) at $2 \mathrm{mg} / \mathrm{mL}$. Three chips were incubated with monoclonal anti-CK8/18 antibody (CK3-3E4) from Miltenyi Biotech at three different concentrations (sample A: $25 \mu \mathrm{g} / \mathrm{mL}$, sample B: $50 \mu \mathrm{g} / \mathrm{mL}$, and sample C: $100 \mu \mathrm{g} / \mathrm{mL}$ ) at $4^{\circ} \mathrm{C}$ overnight and then they were washed three times with PBS $1 x$ and once with deionized water. As experimental control for detection assay one chip was functionalized up to $\operatorname{PrA}$ (sample D).

2.2. Cell Culture. The human prostate androgen-independent PC3 cell line was obtained by ATCC. PC3 cells were grown in DMEM supplemented with $10 \%$ heat-inactivated fetal bovine serum, $20 \mathrm{mM}$ HEPES, $100 \mathrm{U} / \mathrm{mL}$ penicillin, $100 \mathrm{mg} / \mathrm{mL}$ streptomycin, $1 \%$ L-glutamine, and $1 \%$ sodium pyruvate. Cells were cultured at $37^{\circ} \mathrm{C}$ in a $5 \% \mathrm{CO}_{2}-95 \%$ air environment in a humidified incubator.

2.3. Immobilization of PC3 Cells. Samples A, B, C, and D were incubated with PC3 cells at a concentration of $5 * 10^{6}$ cells $/ \mathrm{mL}$ in PBS 1x for 2 hours (schematic representation of detection assay of PC3 cells made on silicon-based biosensors was shown in Figure 1) and then biochips were washed three times with PBS $1 \mathrm{x}$ and once with deionized water.

2.4. Peptides Synthesis. Urotensin II (4-11) was obtained by solid-phase peptide synthesis as previously reported [21]. 


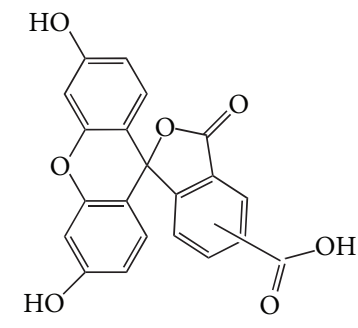

5(6)-Carboxyfluorescein

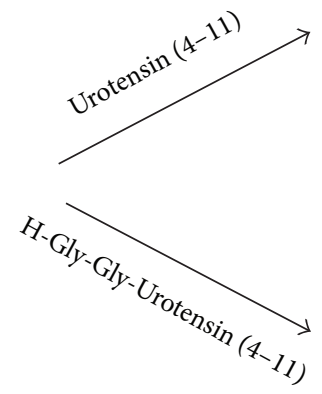

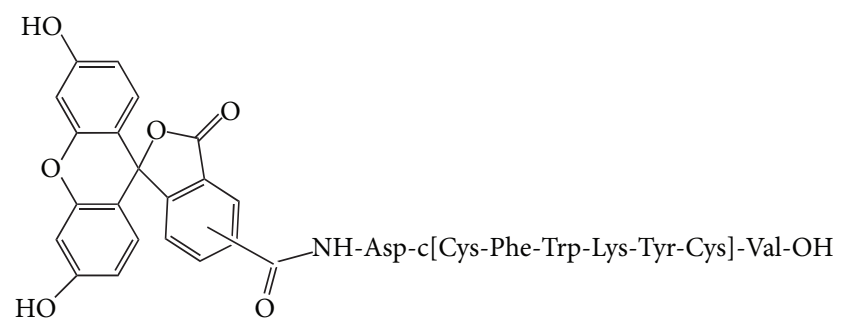

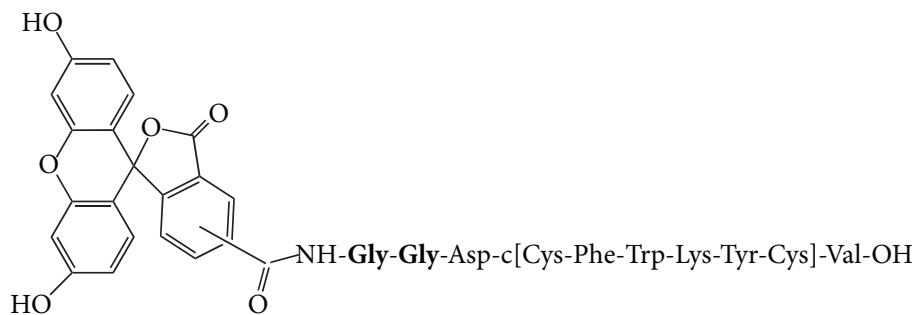

Scheme 1: Synthesis of Urotensin II (4-11) with 5(6)-carboxyfluorescein on solid-phase.

Incorporation of the 5(6)-carboxyfluorescein label at the $\mathrm{N}$ terminal position of Urotensin II (4-11) and H-Gly-GlyUrotensin II (4-11) was performed following the procedure previously reported [22], that is, using 10 equiv of 5(6)carboxyfluorescein (Acros), 10 equiv of HOBt (GL Biochem, China), and HBTU (GL Biochem, China) for $5 \mathrm{~h}$ resulting in a yield of about $65 \%$ in the carboxyfluoresceination reaction. Purification was achieved using a semipreparative reversedphase high-performance liquid chromatography (HPLC) C18 bonded silica column (Vydac 218TP1010; The Separations Group Inc., Hesperia, CA, USA). The purified fluoresceinpeptide was $99 \%$ pure as determined by analytical reversedphase HPLC. The correct molecular weight was confirmed by mass spectrometry and amino acid analysis. Peptide labeling process is reported in Scheme 1.

2.5. Peptide Assay. The peptides were incubated at room temperature for 30 minutes on biochips with higher immobilization of PC3 cells (samples B and C) and then the fluorescence was evaluated. The peptide without spacer arm was incubated on sample $C$ and the peptide with spacer arm on sample B.

2.6. Spectroscopic Ellipsometry. Spectroscopic ellipsometry (SE) measurements were performed by a Jobin Yvon UVISEL-NIR phase modulated spectroscopic ellipsometer apparatus, at an angle of incidence of $65^{\circ}$ over the range $300-1600 \mathrm{~nm}$ with a resolution of $5 \mathrm{~nm}$.

2.7. Optical Microscopy. Optical microscopy analysis was made by means of a Leica DM6000 M microscope equipped by Leica DFC 280 digital camera system. The magnification used for acquisition was $10 \mathrm{x}$ and acquisition of images was made in bright field.

2.8. Fluorescence Microscopy. Fluorescence analysis was performed by means of a Leica Z16 APO fluorescence macroscope equipped with a camera Leica DFC300. The filter
TABLE 1: Spectroscopic ellipsometry measurement of chemical layers growing.

\begin{tabular}{lcccc}
\hline Sample & $d_{\mathrm{ox}}(\mathrm{nm})$ & $d_{\mathrm{APTES}}(\mathrm{nm})$ & $d_{\mathrm{BS} 3}(\mathrm{~nm})$ & $d_{\mathrm{PrA}}(\mathrm{nm})$ \\
\hline $\mathrm{C} 1$ & $32.56 \pm 0.02$ & $6.1 \pm 0.2$ & $0.9 \pm 0.1$ & $1.5 \pm 0.3$ \\
$\mathrm{C} 2$ & $33.17 \pm 0.02$ & $4.83 \pm 0.06$ & $0.6 \pm 0.1$ & $1.3 \pm 0.1$ \\
$\mathrm{C} 3$ & $32.75 \pm 0.01$ & $4.48 \pm 0.08$ & $0.48 \pm 0.03$ & $1.44 \pm 0.04$ \\
$\mathrm{C} 4$ & $32.05 \pm 0.01$ & $5.4 \pm 0.2$ & $0.7 \pm 0.3$ & - \\
\hline
\end{tabular}

used for the acquisition was I3 consisting in a $450-490 \mathrm{~nm}$ bandpass excitation filter, a $510 \mathrm{~nm}$ dichromatic mirror, and a $515 \mathrm{~nm}$ suppression filter.

\section{Results and Discussion}

Functionalization strategy started with evaluation of $\operatorname{PrA}$ concentration needed to homogeneously cover the silicon support surface. PrA properly interacts with the constant fragment $(\mathrm{Fc})$ region of the antibodies [22-24], and thus it allows the right spatial orientation of the antibody on solid supports. PrA has been bound on silicon surface by standard silanization chemistry; the functionalization process is shown in Figure 2. Silanol groups $(\mathrm{Si}-\mathrm{OH})$ were activated by piranha solution, since they are more reactive with respect to $\mathrm{Si}-\mathrm{O}$ Si bonds of silicon dioxide. A self-assembling silane, namely, APTES, has been used in order to obtain a homogeneous amino-terminal surface. The biochips were then treated with a homobifunctional cross-linker, $\mathrm{BS}^{3}$, bringing a sulfo- $N$ hydroxysulfosuccinimide (sulfo-NHS) group that is able to react with primary amines at $\mathrm{pH} 7-9$ to form stable, covalent amide bonds [25]. PrA has primary free amine groups on the side chain of lysine, which can bind sulfo-NHS group on biochip surface.

FITC-labeled PrA was used for functionalization of biochips. Chemically modified surface of biochips was characterized by fluorescence and ellipsometry measurements. Results of spectroscopic ellipsometry are reported in Table 1; 


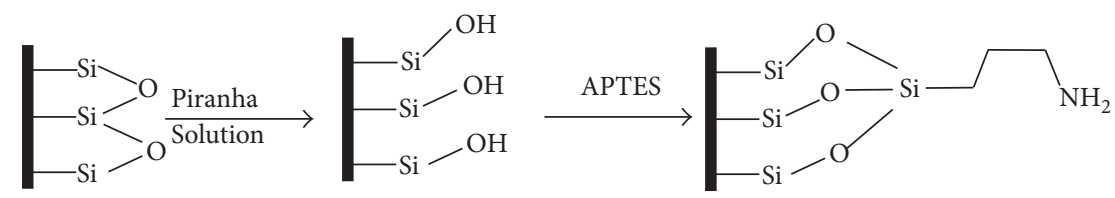

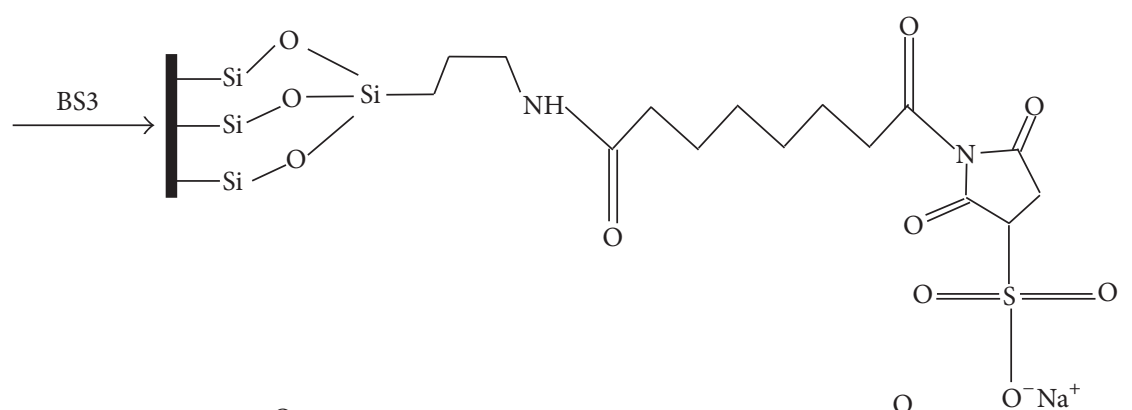

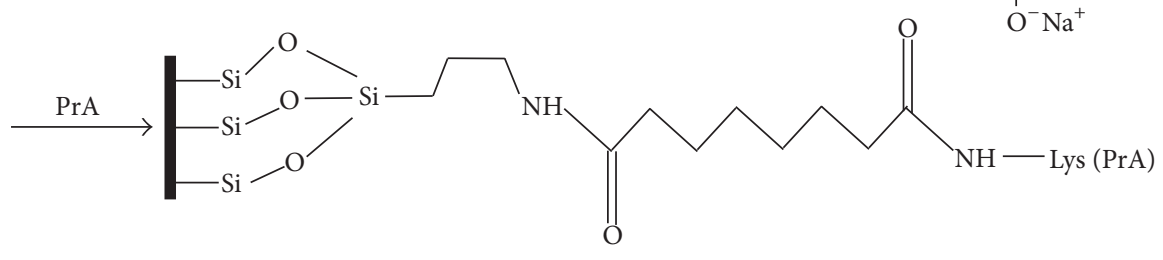

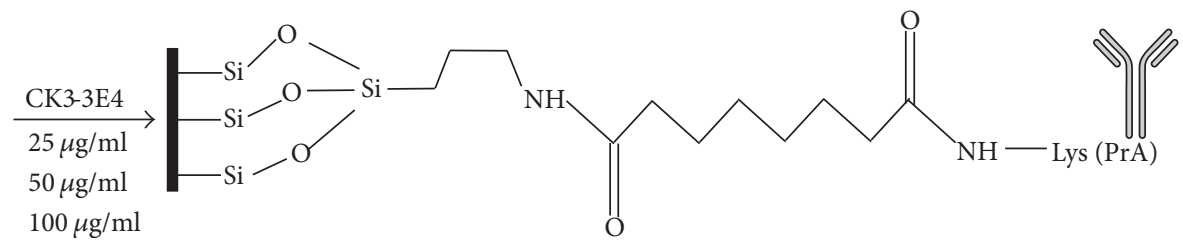

FIGURE 2: Reaction scheme of functionalization process.

in detail, about 5-6 nm of amino-terminal APTES silane is present on each surface and an increase of $0.5-1 \mathrm{~nm}$ due to the addition of $\mathrm{BS}^{3}$ cross-linker can be observed. The quantitative data are obtained by sampling the biochip surface in at least three points; taking into account millimeter dimensions of ellipsometer light spot, we found that the functionalization is quite regular and reproducible on a macroscopic scale, at least for chemical compound layers. Even if the three biochips were functionalized by different concentrations of $\operatorname{PrA}^{*}$, the increase in layers thickness is very similar, ranging from 1.3 to $1.5 \mathrm{~nm}$. In this view, we could conclude that ellipsometric measurements are not useful for evaluation of the best PrA concentration. On the other hand, fluorescence data, shown in Figures 3(a) and 3(b), displayed quite different intensities of fluorescence: sample $\mathrm{Cl}$ (chip functionalized by $1 \mathrm{mg} / \mathrm{mL}$ concentration of $\operatorname{PrA}^{*}$ ) had a fluorescence (fluorescence intensity $=370.9$ a.u.) lower than sample C2 and consequently a lower degree of functionalization; sample C2 $(2 \mathrm{mg} / \mathrm{mL}$ concentration of $\operatorname{PrA}^{*}$ ) showed the presence of homogeneous and strong fluorescence (fluorescence intensity $=389.8$ a.u.); sample C3 (chip with $3 \mathrm{mg} / \mathrm{mL}$ concentration of $\operatorname{PrA}^{*}$ ) presented clearly visible fluorescent clusters, which explain the highest fluorescence observed (fluorescence intensity = 460.8 a.u.) but also represent an excess of PrA that makes the surface poorly homogenous. The control sample C4 (functionalized up to $\mathrm{BS}^{3}$ ) did not show any autofluorescence (fluorescence intensity = 9.7 a.u.). Quantitative fluorescence data
TABLE 2: Cell counting of immobilized cells made by ImageJ software.

\begin{tabular}{lc}
\hline Sample & Number of cells \\
\hline A $(25 \mu \mathrm{g} / \mathrm{mL}$ of CK3-3E4) & 693 \\
B $(50 \mu \mathrm{g} / \mathrm{mL}$ of CK3-3E4) & 3604 \\
C $(100 \mu \mathrm{g} / \mathrm{mL}$ of CK3-3E4) & 6858 \\
D (CTR) & 83 \\
\hline
\end{tabular}

were summarized in Figure 3(b). As a result of homogeneous and good degree of functionalization, silicon biochips were functionalized by $2 \mathrm{mg} / \mathrm{mL} \operatorname{PrA}$ in subsequent experiments.

In the last step of biochip functionalization (Figure 2), three different concentrations of antibody anti-CK8/18 (CK33E4) were tested in order to evaluate biochips sensitivity after interaction with PC3 cells that express CK8/18 on their membrane. The specificity of CK3-3E4 antibody was previously tested by performing FACS analysis on blood samples, as shown in Figure 7 where the binding event between the cells expressing CK8/18 and the antibody CK3-3E4 is evident. After PC3 cells incubation, silicon surfaces were observed through optical microscopy and cells automatically counted by ImageJ freeware software (Table 2). Due to functionalization with different antibodies concentrations, biochips showed very distinct ability in cell capture (Figure 4): biochip with lower concentration of CK3-3E4 (sample A) showed 

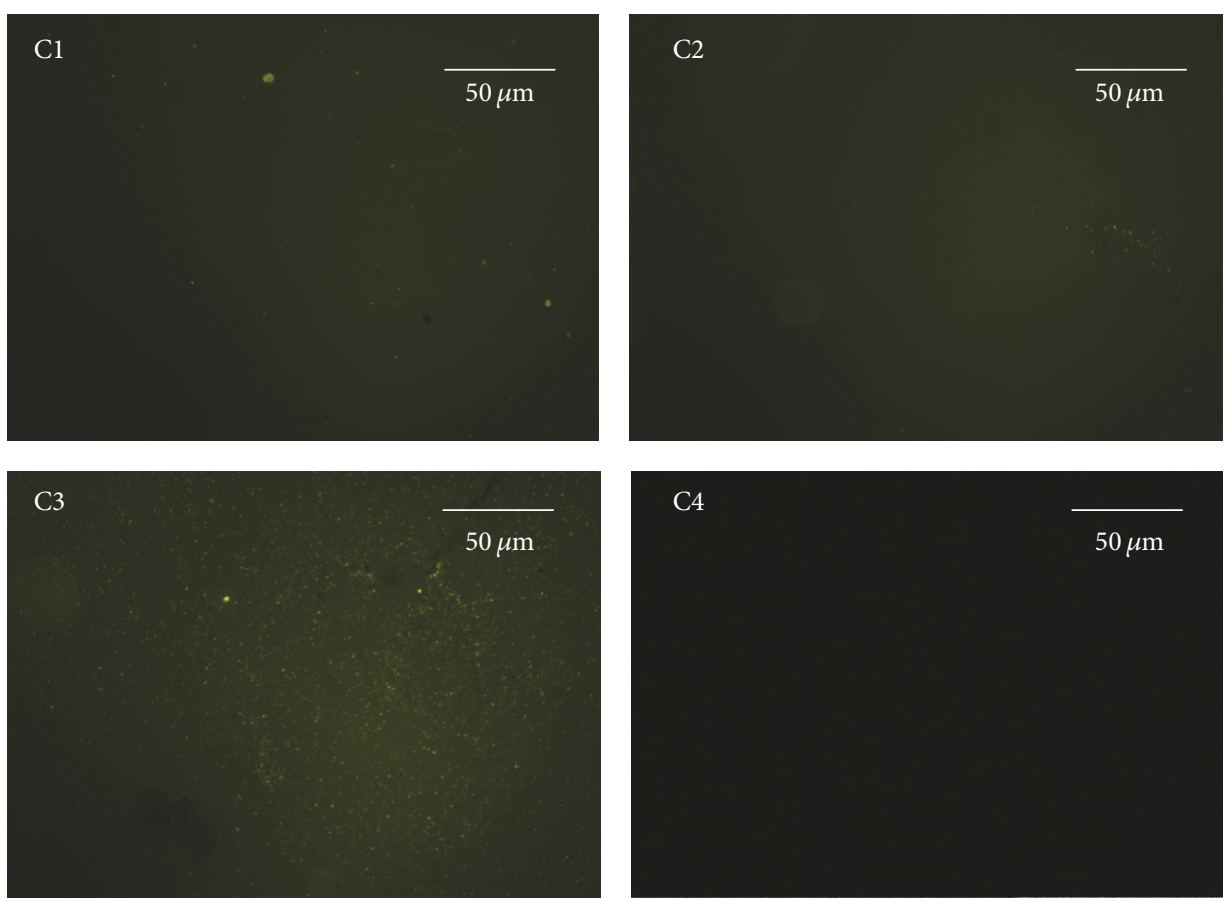

(a)

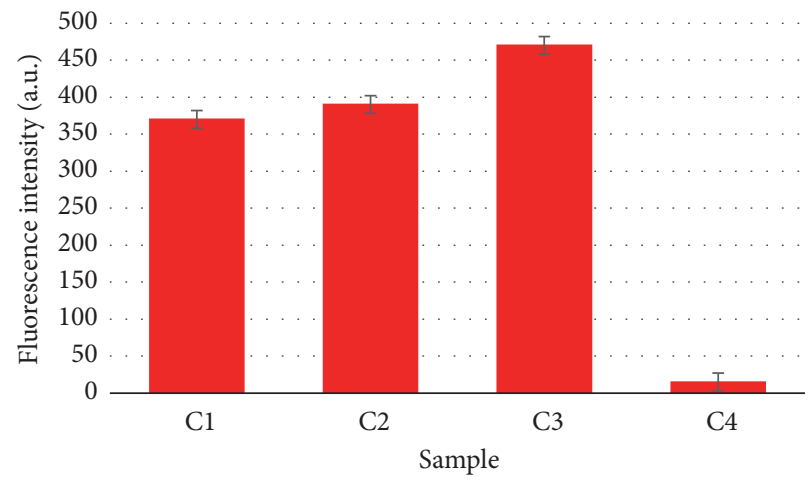

(b)

Figure 3: (a) Images of biochips fluorescence after fluorescent PrA binding. Sample C1: biochip functionalized with PrA* at $1 \mathrm{mg} / \mathrm{mL}^{*}$ Sample C2: biochip functionalized with $\operatorname{PrA}^{*}$ at $2 \mathrm{mg} / \mathrm{mL}$. Sample C3: biochip functionalized with $\operatorname{PrA}^{*}$ at $3 \mathrm{mg} / \mathrm{mL}$. Sample C4: reference biochip functionalized up to $\mathrm{BS}^{3}$. In all images, error bar is $50 \mu \mathrm{m}$. (b) Histogram representation for fluorescence intensity of samples obtained by ImageJ software.

poor ability in binding cells, while biochips with higher concentrations of CK3-3E4 (sample B and C) presented increasing ability in blocking cells. The control biochip, functionalized up to PrA (sample D), was not able at all to detect cells. By plotting these data, we can estimate a kind of device theoretical sensitivity relative to the ratio cells captured/antibody concentration. Figure 8 shows plot representation of cells number that was immobilized on biochips against antibody concentration used during functionalization process. OriginLab software was used to fit experimental points in Figure 7 by the following equation:

$$
y=\frac{a}{1+b e^{-k x}} .
$$

The first derivative of (1) is an estimation of sensitivity:

$$
\begin{aligned}
& \frac{d y}{d x}=a \cdot \frac{k}{4}=157.5 \pm 0.6 \operatorname{cell} /(\mu \mathrm{g} / \mathrm{mL}) \\
&(a=6924 \pm 5, k=0.0910 \pm 0.0003)
\end{aligned}
$$

Functionalized biochips can be considered the first example of a lab-on-chip device for the detection of circulating PC3 cells. In order to avoid false positives due to aspecific binding event between biochip surface and other circulating cells, we proposed a cell recognition assay through the use of synthetic fluorescently labeled peptides that specifically bind UTR on cell membrane. The specific binding of this labeled peptide 

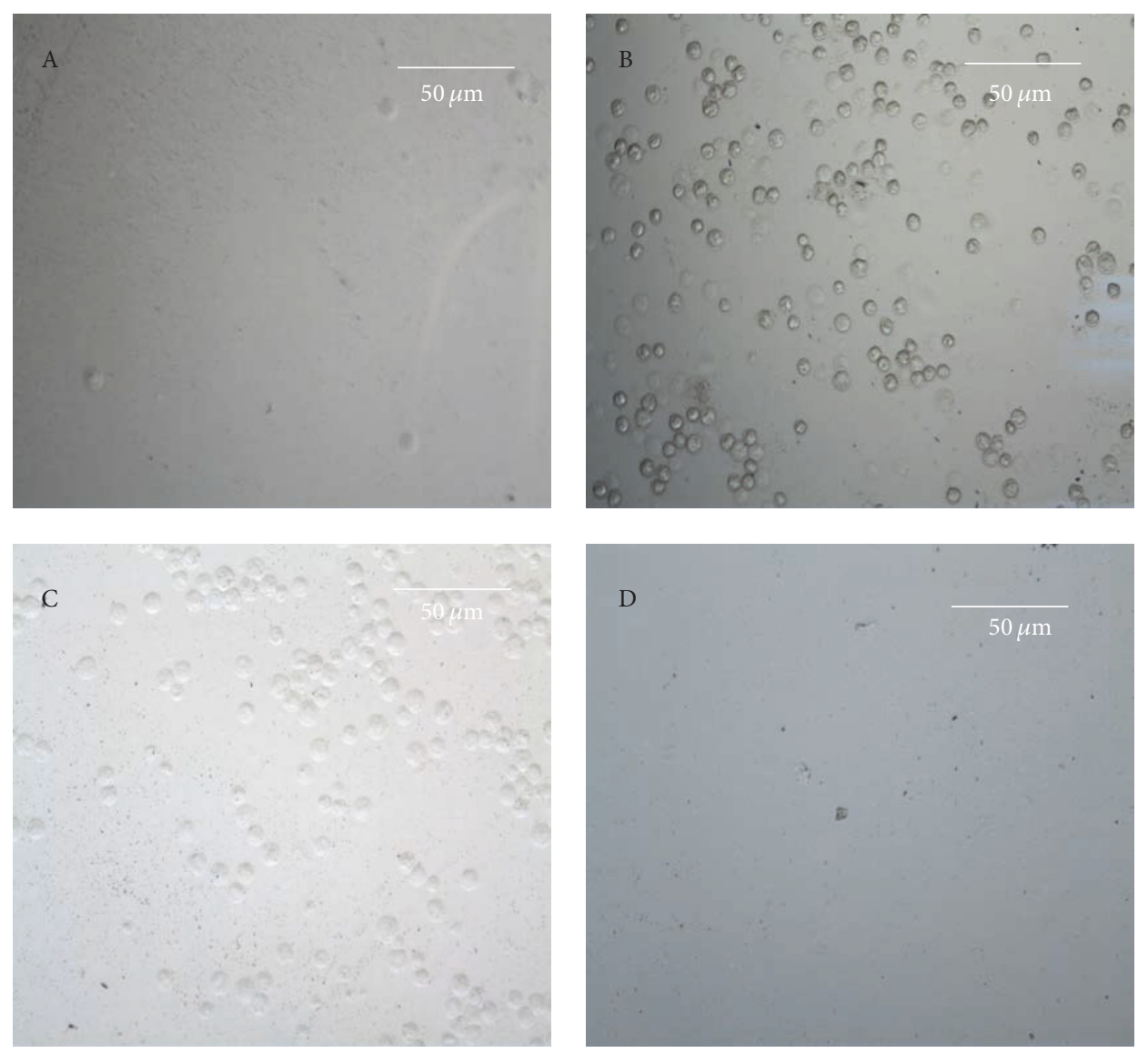

FIgURE 4: Optical microscopy images after PC3 cells immobilization. Sample A: biochip functionalized with antibody concentration at $25 \mu \mathrm{g} / \mathrm{mL}$. Sample B: biochip functionalized with antibody concentration at $50 \mu \mathrm{g} / \mathrm{mL}$. Sample C: biochip functionalized with antibody concentration at $100 \mu \mathrm{g} / \mathrm{mL}$. Sample D: biochip functionalized up to PrA. In all images, error bar is $50 \mu \mathrm{m}$.

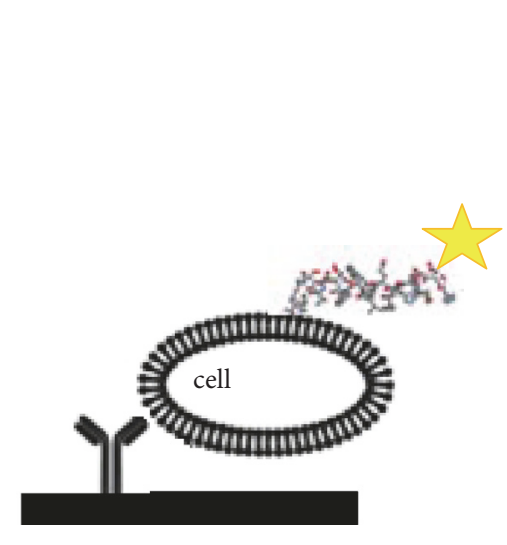

(a)

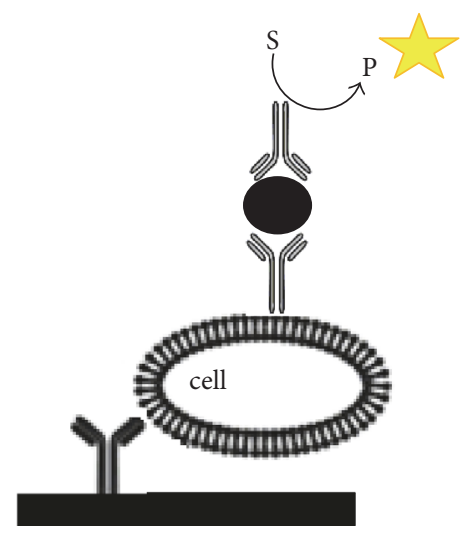

(b)

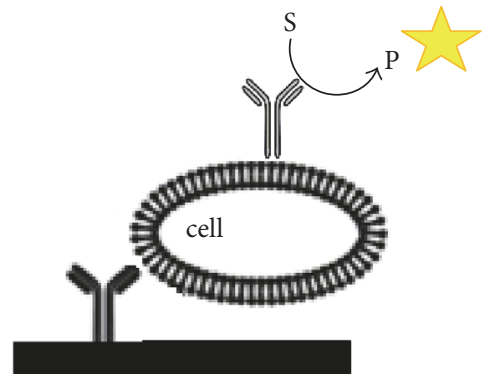

(c)

FIGURE 5: Schematic representation of (a) peptide assay made on generic cell immobilized on biosensor, (b) direct ELISA immunoassay made on generic cell immobilized on biosensor, and (c) sandwich ELISA immunoassay made on generic cell immobilized on biosensor. The schematization is in scale.

to UTR was previously demonstrated by performing binding assay [15] [patent PCT/EP2008/051541].

A schematic representation of this assay compared with common ELISA immunoassays is represented in Figure 5. The peptide assay is one step and needs only one fluorescently labeled peptide (Figure 5(a)), whereas sandwich ELISA (Figure 5(b)) needs antibody bound on plate surface that interacts with antigen on cell membrane and then an enzyme-linked antibody that produces labeled complexes (at least a threestep assay), and direct ELISA immunoassay (Figure 5(c)) 

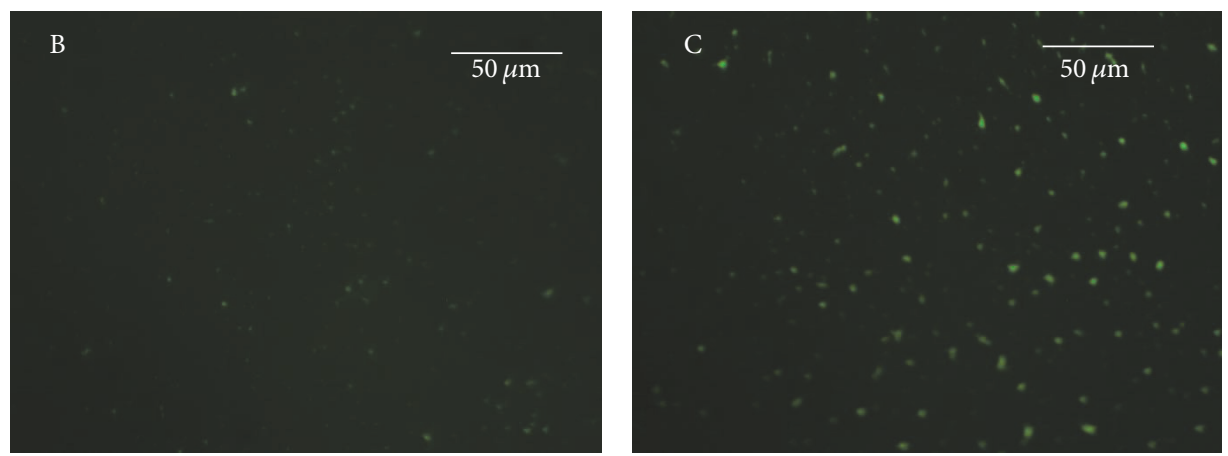

(a)

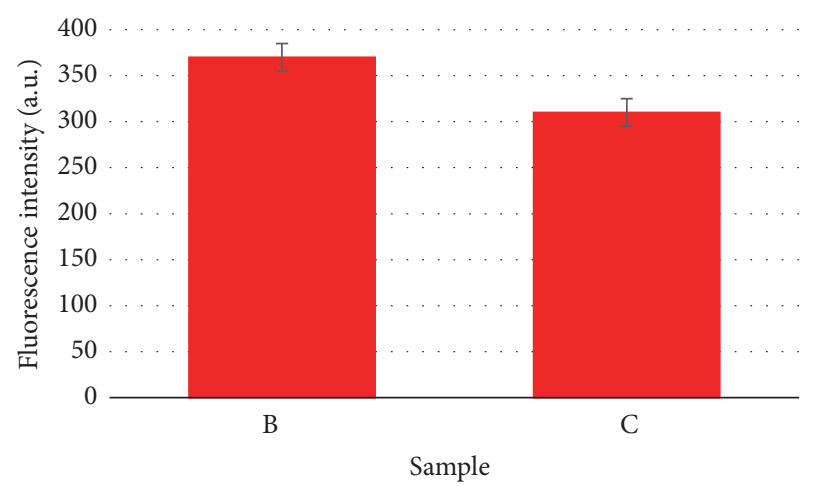

(b)

FIGURE 6: (a) Images of biochips fluorescence after FITC-labeled peptides binding. Sample B: biochip functionalized with antibody concentration at $50 \mu \mathrm{g} / \mathrm{mL}$ and bonded with peptides with spacer arm. Sample C: biochip functionalized with antibody concentration at $100 \mu \mathrm{g} / \mathrm{mL}$ and bonded with peptides without spacer arm. In both images, error bar is $50 \mu \mathrm{m}$. (b) Histogram representation for fluorescence intensity of samples obtained by ImageJ software.

uses antibody linked to enzyme that converts an uncolored substrate in a labeled product (a two-step process) [26]. Both ELISA immunoassays require high costs for reagents and long times for performing experiments; on the contrary, the proposed peptide assay requires only one incubation with the labeled peptide, so that it could be fast and cheap. In detail, two FITC-labeled peptides were used for cell recognition after PC3 immobilization on biochip surface. The peptides used represent two forms of fluorescent human Urotensin II (4-11); one was synthetized with a spacer arm (Gly-Gly) and the other one without it, as reported in Scheme 1. Figure 6 shows fluorescence images of sample B incubated with spacer arm peptide and sample $C$ incubated with peptide synthesized without spacer arm together with their, respectively, fluorescence intensities. Even if sample B shows a fluorescence intensity quantitatively greater than sample $\mathrm{C}$ (fluorescence intensity of sample B is 391 a.u.; fluorescence intensity of sample C is 359 a.u.), the background fluorescence due to binding of peptide with surface must be taken into account. Sample C clearly exhibits a higher fluorescence signal on immobilized cells and lower background fluorescence. Even if both peptides identify PC3 cells bound on the biochip surface, these results demonstrate that peptide synthesized without spacer arm is more efficient and specific against false positives.

\section{Conclusions}

In this experimental work, we explored the functionalization strategy for detecting prostate cancer PC3 cells on crystalline silicon biochip. Recent studies demonstrated that Urotensin II receptor predicts the clinical outcome of prostate cancer patients, so it is a helpful biomarker for PC3 recognition. Spectroscopic ellipsometry and fluorescent microscopy quantified the thickness of biochemical layers and the roughness of surfaces. Optical microscopy demonstrated that PC3 cell line could bind functionalized solid support and the number of detected cells critically depended on concentration of anticytokeratin 8/18 grafted on silicon surface. Furthermore, fluorescence data confirmed the use of synthetic labeled Urotensin II (4-11) in rapid, easy, and low cost assay for PC3 cells recognition due to their ability to bind selectively UTR on cells membrane. These results demonstrated that the proposed strategy could be really useful as diagnostic system for prostate cancer. Moreover, even if the PC3 circulating cells could be really few, there are a lot of microfluidic 


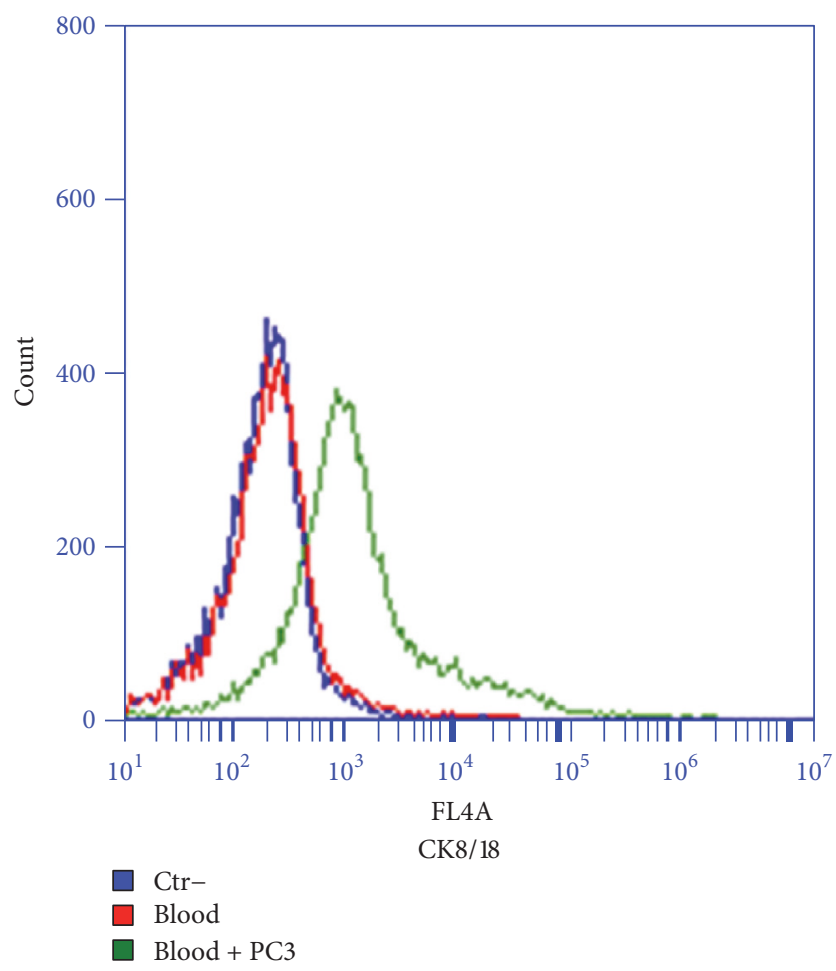

FIGURE 7: FACS characterization of cell expressing CK8/18 bound by CK3-3E4.

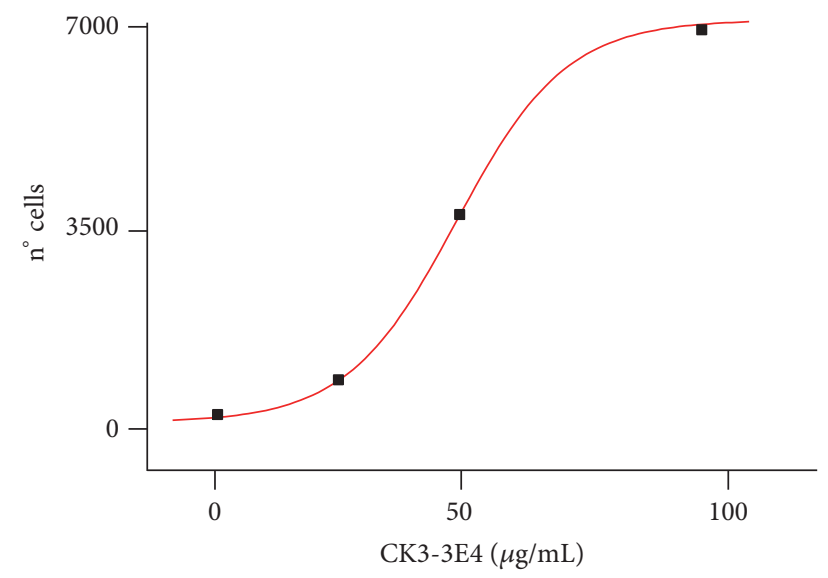

FIGURE 8: Fitting of counted cell versus antibody concentration.

implemented methods to concentrate these cells and thus make the proposed diagnostic test feasible [27].

\section{Conflicts of Interest}

The authors declare that there are no conflicts of interest regarding the publication of this paper.

\section{Acknowledgments}

The authors gratefully thank Dr. Monica Terracciano for interesting discussion about functionalization process.

\section{References}

[1] S. Loeb and W. J. Catalona, "What to do with an abnormal PSA test," Oncologist, vol. 13, no. 3, pp. 299-305, 2008.

[2] M. Cristofanilli, G. T. Budd, M. J. Ellis et al., "Circulating tumor cells, disease progression, and survival in metastatic breast cancer," The New England Journal of Medicine, vol. 351, no. 8, pp. 781-791, 2004.

[3] M. Feldstein and M. Zelen, "Inferring the natural time history of breast cancer: Implications for tumor growth rate and early detection," Breast Cancer Research and Treatment, vol. 4, no. 1, pp. 3-10, 1984.

[4] C. J. Logothetis, N. M. Navone, and S.-H. Lin, "Understanding the biology of bone metastases: Key to the effective treatment of prostate cancer," Clinical Cancer Research, vol. 14, no. 6, pp. 1599-1602, 2008.

[5] I. G. McIntyre, K. Spreckley, and R. B. Clarke, "Optimization of the reverse transcriptase polymerase chain reaction for the detection of circulating prostate cells," British Journal of Cancer, vol. 83, pp. 992-997, 2000.

[6] S. Tai, Y. Sun, J. M. Squires et al., "PC3 is a cell line characteristic of prostatic small cell carcinoma," Prostate, vol. 71, no. 15, pp. 1668-1679, 2011.

[7] P. R. Dodds, V. J. Caride, and B. Lytton, “The role of vertebral veins in the dissemination of prostatic carcinoma," The Journal of Urology, vol. 126, no. 6, pp. 753-755, 1981.

[8] G. Sardana, K. Jung, C. Stephan, and E. P. Diamandis, "Proteomic analysis of conditioned media from the PC3, LNCaP, and 22Rvl prostate cancer cell lines: discovery and validation of candidate prostate cancer biomarkers," Journal of Proteome Research, vol. 7, no. 8, pp. 3329-3338, 2008.

[9] P. S. Steeg, "Tumor metastasis: mechanistic insights and clinical challenges," Nature Medicine, vol. 12, no. 8, pp. 895-904, 2006.

[10] H. T. Tan, J. Low, S. G. Lim, and M. C. M. Chung, "Serum autoantibodies as biomarkers for early cancer detection," The FEBS Journal, vol. 276, no. 23, pp. 6880-6904, 2009.

[11] M. Marra, G. Salzano, C. Leonetti et al., "Nanotechnologies to use bisphosphonates as potent anticancer agents: the effects of zoledronic acid encapsulated into liposomes," Nanomedicine: Nanotechnology, Biology, and Medicine, vol. 7, no. 6, pp. 955964, 2011.

[12] M. Caraglia, A. Budillon, P. Tagliaferri, M. Marra, A. Abbruzzese, and F. Caponigro, "Isoprenylation of intracellular proteins as a new target for the therapy of human neoplasms: Preclinical and clinical implications," Current Drug Targets, vol. 6, no. 3, pp. 301-323, 2005.

[13] M. Caraglia, M. Marra, C. Leonetti et al., "R115777 (Zarnestra $^{\circledR}$ )/zoledronic acid (Zometa ${ }^{\circledR}$ ) cooperation on inhibition of prostate cancer proliferation is paralleled by Erk/Akt inactivation and reduced $\mathrm{Bcl}-2$ and bad phosphorylation," Journal of Cellular Physiology, vol. 211, no. 2, pp. 533-543, 2007.

[14] R. Moll, W. W. Franke, D. L. Schiller, B. Geiger, and R. Krepler, "The catalog of human cytokeratins: patterns of expression in normal epithelia, tumors and cultured cells," Cell, vol. 31, no. 1, pp. 11-24, 1982.

[15] P. Grieco, R. Franco, G. Bozzuto et al., "Urotensin II receptor predicts the clinical outcome of prostate cancer patients and is involved in the regulation of motility of prostate adenocarcinoma cells," Journal of Cellular Biochemistry, vol. 112, no. 1, pp. 341-353, 2011.

[16] F. S. Ligler and C. A. Rowe Taitt, Optical Biosensors, Elsevier, Amsterdam, Netherlands, 2004. 
[17] A. F. Collings and F. Caruso, "Biosensors: recent advances," Reports on Progress in Physics, vol. 60, no. 11, pp. 1397-1445, 1997.

[18] S. U. Senveli and O. Tigli, "Biosensors in the small scale: methods and technology trends," IET Nanobiotechnology, vol. 7, no. 1, pp. 7-21, 2013.

[19] M. Tweedie, R. Subramanian, P. Lemoine et al., "Fabrication of impedimetric sensors for label-free Point-of-Care immunoassay cardiac marker systems, with passive microfluidic delivery," in Proceedings of the Conference Proceedings. Annual International Conference of the IEEE Engineering in Medicine and Biology Society, pp. 4610-4614, New York, NY, USA, August 2006.

[20] M. Vestergaard, K. Kerman, and E. Tamiya, "An overview of label-free electrochemical protein sensors," Sensors, vol. 7, no. 12, pp. 3442-3458, 2007.

[21] P. Grieco, A. Carotenuto, P. Campiglia et al., "A new, potent urotensin II receptor peptide agonist containing a Pen residue at the disulfide bridge," Journal of Medicinal Chemistry, vol. 45, no. 20, pp. 4391-4394, 2000.

[22] A. Lamberti, C. Sanges, N. Migliaccio et al., "Silicon-based technology for ligand-receptor molecular identification," Journal of Atomic, Molecular, and Optical Physics, vol. 2012, Article ID 948390, 5 pages, 2012.

[23] A. Lamberti, C. Sanges, L. Rotiroti et al., "The ligand-receptor interactions based on silicon technology," Current Topics in Biotechnology, vol. 5, pp. 49-54, 2009.

[24] J. W. Goding, "Use of staphylococcal protein A as an immunological reagent," Journal of Immunological Methods, vol. 20, no. C, pp. 241-253, 1978.

[25] G. Mattson, E. Conklin, S. Desai, G. Nielander, M. D. Savage, and S. Morgensen, "A practical approach to crosslinking," Molecular Biology Reports, vol. 17, no. 3, pp. 167-183, 1993.

[26] D. G. Wild, The Immunoassay Handbook: Theory and Applications of Ligand Binding, ELISA and Related Techniques, Elsevier, Amsterdam, Netherlands, 2013.

[27] M. E. Warkiani, B. L. Khoo, D. S.-W. Tan et al., "An ultra-highthroughput spiral microfluidic biochip for the enrichment of circulating tumor cells," Analyst, vol. 139, no. 13, pp. 3245-3255, 2014. 


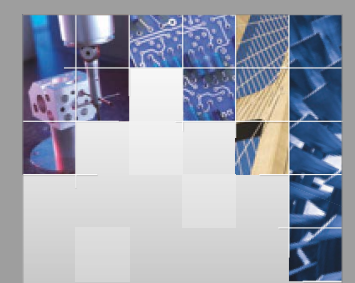

\section{Enfincering}
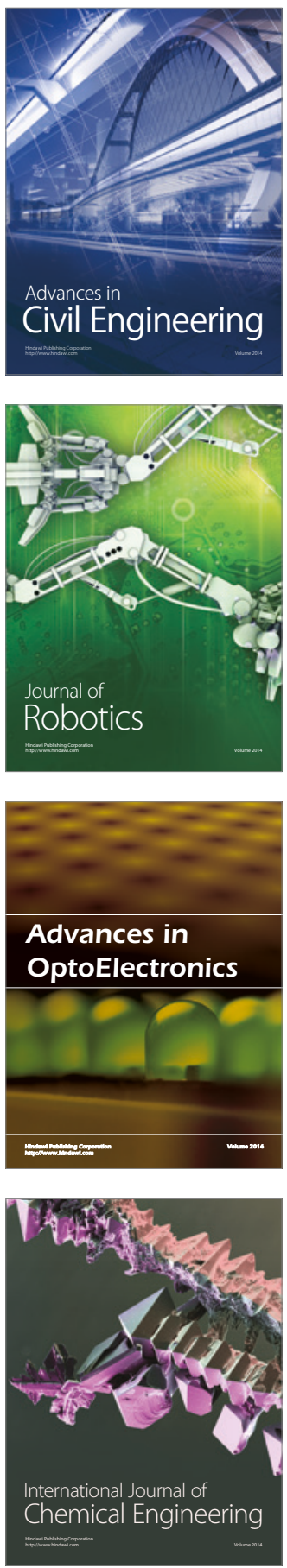

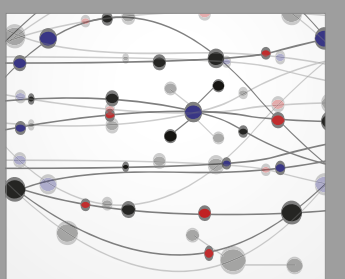

The Scientific World Journal

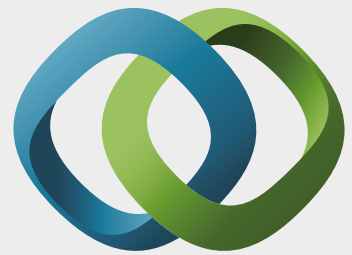

\section{Hindawi}

Submit your manuscripts at

https://www.hindawi.com
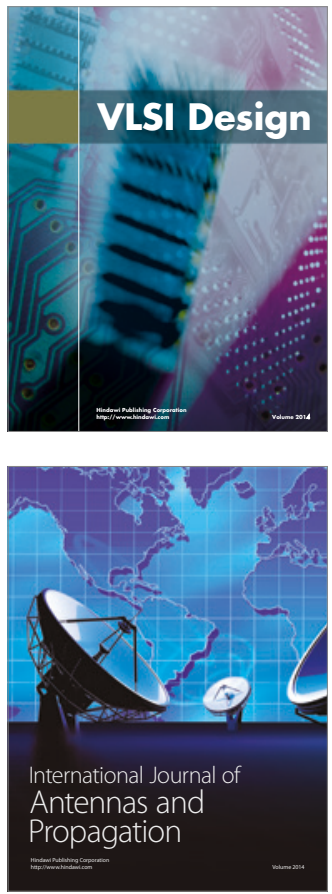

\section{Rotating}

Machinery
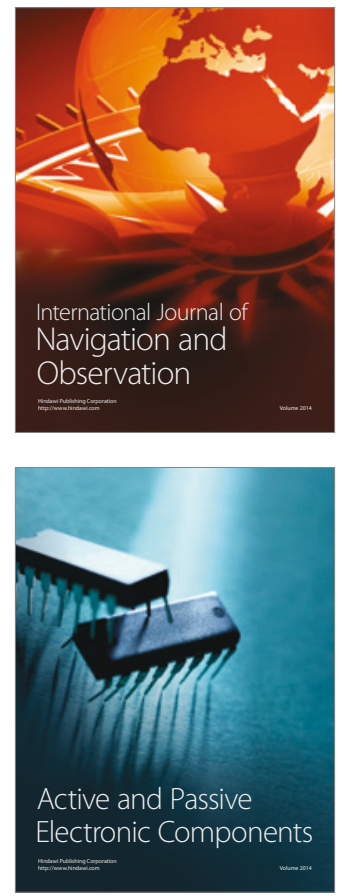
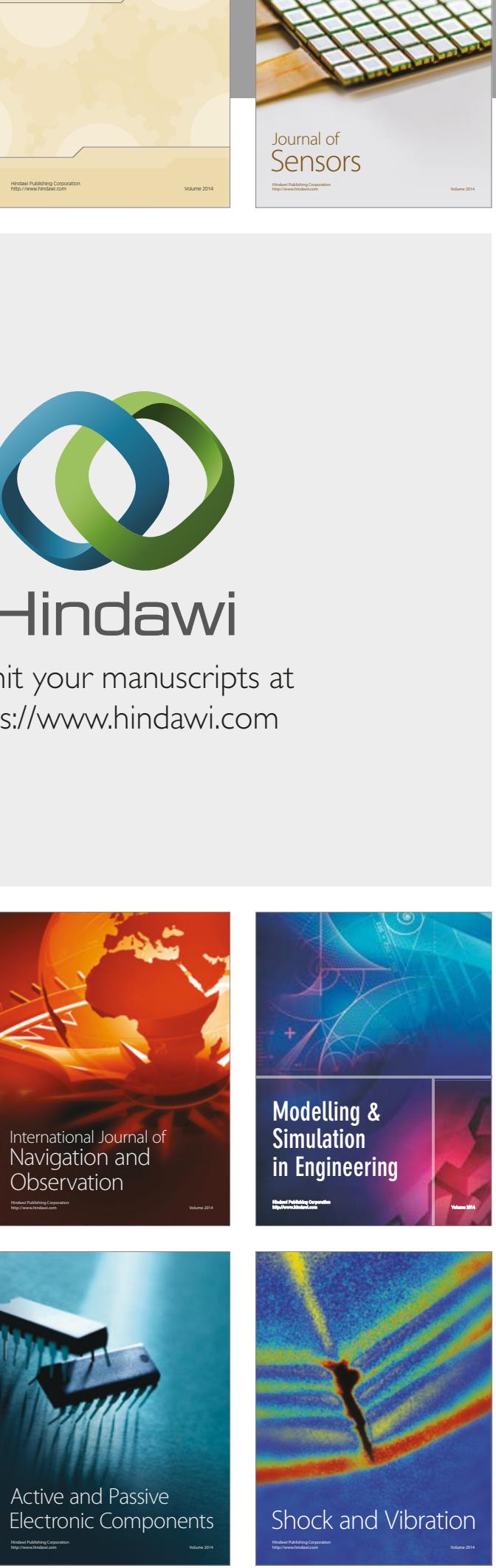
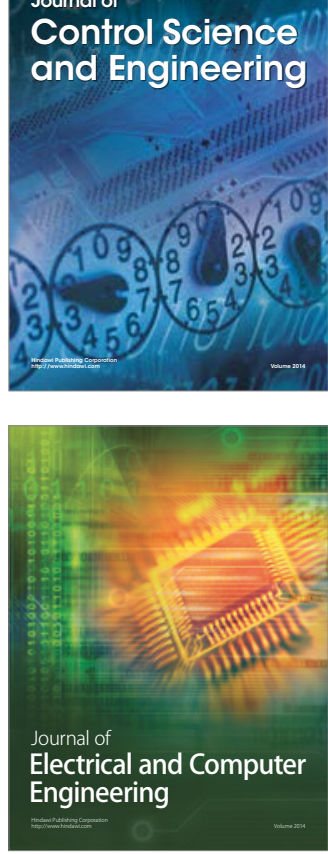

Distributed

Journal of

Control Science

and Engineering
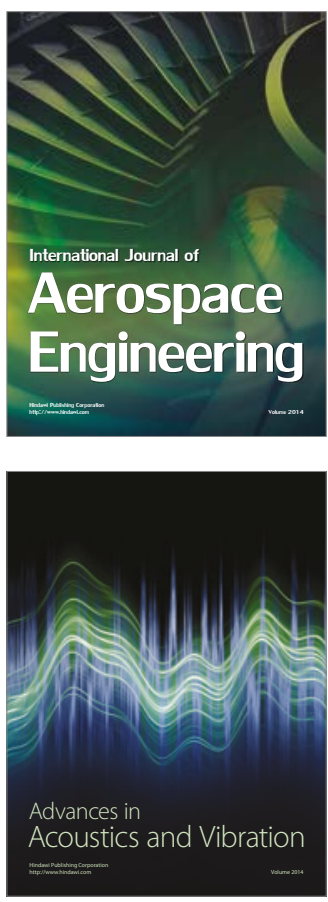

Sensor Networks 